\title{
Dye decolorizing potential of a novel fungus Coriolus versicolor ML04 in the medium optimized by response surface methodology
}

\author{
Chidambaram Kulandaisamy Venil* and Perumalsamy Lakshmanaperumalsamy \\ Department of Microbiology, School of Life Sciences, Karpagam University, Coimbatore - 641 021, \\ Tamil Nadu, India.
}

\begin{abstract}
The potential of the white rot fungus, Coriolus versicolor MLO4 to decolorize the widely used textile dye Blue BB was tested by employing statistical optimization. Response surface methodology (RSM) involving a central composite design (CCD) was applied to evaluate the interactive effects of four significant factors in different ranges i.e., glucose $(0.5-2.5 \mathrm{~g} / \mathrm{L})$, yeast extract $(0.4-1.2 \mathrm{~g} / \mathrm{L})$, dye concentration $(100-500$ ppm) and inoculum size $(5-$ $20 \% \mathrm{v} / \mathrm{v})$ to decolorize the Blue BB. The results demonstrated the effectiveness of the statistical experimental design and the ability of $\mathrm{C}$. versicolor MLO4 for maximum dye decolorization (>96\%) at the optimum conditions of the significant factors.
\end{abstract}

Keywords: Blue BB; Coriolus versicolor ML04; Plackett - Burman design; central composite design

\section{INTRODUCTION}

Synthetic dyes are extensively used in textile, leather, food, cosmetics, pharmaceutical and paper industries and more than $7 \times 10^{5}$ tons of these dyes are produced annually worldwide (Keck et al., 1997). As most of the synthetic dyes are of chemical contents, discharge of such dyes into environment poses significant environmental problems. One of the environmental problems is the contamination of water sources by dyestuff effluents discharged by industries, which results in immense health predicament to all life forms. Various methods of treatment of such dye contaminated water sources are now being attempted to prevent the deterioration of our ecosystem
A number of physicochemical methods, such as adsorption, coagulation, precipitation, filtration, and oxidation, have been used to treat the dyestuff effluents, but these methods have many limitations. Alternately, the biological methods are of great value as such methods are inexpensive, ecofriendly and have less sludge producing properties. Currently, extensive research is focused to find optimal microbial biomass, which is as cheap as possible for the removal of contaminating dyes from large volumes of polluted water (Jadhav and Govindwar, 2006). For bioremediation of synthetic dye effluents, several microorganisms, including bacteria and fungi can be employed. Many microorganisms have been reported for their ability to decolorize the dyes (Chang et al., 2001; Khehra et al., 2005). Anaerobic and

*Author for correspondence: ckvenil@gmail.com 
microaerophilic microorganisms have been found to reduce the dye bonds, non specifically in anaerobic conditions leading to dye decolorization (Coughlin et al., 1999). Among the microorganisms, white-rot fungi are the most intensively studied dye decolorizing microorganisms (Wesenberg et al., 2003). Fungi are recognized for their superior aptitudes to produce a large variety of extracellular proteins, organic acids and other metabolites and for their capacities to adapt to severe environmental constraints. Beyond the production of such relevant metabolites, fungi have been attracting a growing interest for the biotreatment of waste water. Fungi with their ligninolytic enzyme systems are also being applied in the biological decolorization of textile dyestuff effluents (Lacina et al., 2003). Coriolus versicolor showed varying decolorizing capacity to remove dyes from industrial effluents (Wesenberg et al., 2003).

The objectives of this study were to screen a potent fungus capable of degrading the dye Blue BB and optimize the medium conditions and factors through response surface methodology for maximum dye decolorization.

\section{MATERIALS AND METHODS}

\section{Dyes and chemicals}

The dye Blue BB, a commercial grade dye was locally procured and utilized.

\section{Organisms and culture conditions}

The fungal strain was isolated from the textile dye contaminated soil collected within the premises of a textile industry and it was identified as Coriolus versicolor ML04. The culture was grown at $30{ }^{\circ} \mathrm{C}$ in Sabouraud's dextrose broth $(\mathrm{g} / \mathrm{L}$ : Peptone, 10; Dextrose, 40) and was subjected as a biological agent to test the decolorization of the dye Blue BB.

\section{Decolorization experiments}

Preliminary experiments for dye decolorization were carried out in triplicate in $100 \mathrm{ml}$ Erlenmeyer flasks. In each flask, a dye (Blue BB) concentration of $50 \mathrm{mg} / \mathrm{L}$ was taken as standard concentration at $30{ }^{\circ} \mathrm{C}$ and $\mathrm{pH}$ 5.0. Four millimeter of fungal mycelium was inoculated using cork borer into each flask. A control flask with all the components, except the fungal mat was maintained in parallel to obtain the abiotic decolorization, if any. All the experiments as well as controls were run in triplicate. The flasks were incubated at $28{ }^{\circ} \mathrm{C}$ for five days. Four milliliter of mixed liquor was drawn from the flask at $24 \mathrm{~h}$ interval and was centrifuged at 10,000 rpm for 10 min to separate the fungal biomass. Dye (Blue BB) clearance from the culture fluid (supernatant) was monitored by assaying at $\mathrm{A}_{600}$.

\section{Experimental design}

Screening of important nutrient components using Plackett - Burman design

The medium components were screened for eleven variables at two levels, maximum (+) and minimum (-) (Plackett and Burman, 1946). The experimental design and levels of each variable are shown in Table 1. The medium was formulated as per the design and the flask culture experiments for dye decolorization were assayed as described earlier (2.3). Response was calculated as the rate of dye decolorization and expressed as \% decolorization. All the experiments were performed in triplicate and the average of the rate of the decolorization was considered as the response.

The effect of each variable was calculated using the following equation:

$$
\mathrm{E}=\left(\sum \mathrm{M}_{+}-\sum \mathrm{M}_{-}\right) / \mathrm{N}
$$

\section{Optimizaion of the screened medium components using response surface methodology}

The screened medium components affecting the dye decolorization were optimized using central composite design (CCD) (Box \& Wilson, 1951; Box \& Hunter, 1957). Four important parameters, i.e., concentration of glucose (X1), yeast extract (X2), dye (X3) and inoculum size (X4), were screened from Plackett - Burman design as the independent variables and percentage of decolorization was the dependent response variable. Each of the four independent variables was studied at five different levels as per CCD in a total of 30 experiments. The percentage of dye decolorization corresponding to combined effects of four variables was studied in their specified ranges: glucose: $0.5-2.5(\mathrm{~g} / \mathrm{L})$, yeast extract: 0.4 $-1.2 \mathrm{~g} / \mathrm{L}$, dye concentration: $100-500 \mathrm{ppm}$ and inoculum size: $5-20(\% \mathrm{v} / \mathrm{v})$. The other two process variables, $\mathrm{pH}$ and temperature were kept constant at 6 and $30{ }^{\circ} \mathrm{C}$, respectively throughout the 30 experiments. The plan of CCD in coded 
levels of the four independent variables is as shown in Table 3.

According to this design, the total number of treatment combinations was $2^{k}+2 k+n 0$ where ' $k$ ' was the number of independent variables and $n 0$ the number of repetitions of the experiments at the center point. For statistical calculation, the variables $X_{i}$ were coded as $x_{i}$ according to the following transformation:

$\mathrm{X}_{\mathrm{i}}=\mathrm{X}_{\mathrm{i}}-\mathrm{X}_{0} / \delta \mathrm{X}$

\section{Validation of the experimental model}

The statistical model was validated with respect to dye decolorization under the conditions predicted by the model in flask conditions. The samples were withdrawn at the desired intervals and dye decolorization assay was determined as described above.

\section{RESULTS AND DISCUSSION}

The new isolate $C$. versicolor ML04 was able to decolorize the dye Blue BB using it as the sole source of carbon and energy. While performing the medium optimization studies for obtaining maximum decolorization, glucose was the best carbon source amongst various carbon sources tested, supporting the maximum decolorization (Mohana et al., 2007).

The interaction of eleven medium factors namely lactose, glucose, $\left(\mathrm{NH}_{4}\right)_{2} \mathrm{SO}_{4}, \mathrm{NH}_{4} \mathrm{NO}_{3}$, tryptone, yeast extract, dye concentration, inoculum size, incubation period, $\mathrm{CaCl}_{2}$ and $\mathrm{MnSO}_{4}$ in dye decolorization investigated in 12 runs using Plackett - Burman design is presented in Table 1. The data indicated a wide variation in the dye decolorization, ranging from 31.40 to $79.36 \%$. This variation reflected the effect of the interaction among the variables in the dye decolorization. Among the variables screened, the most effective factors with high significance level were in the order of glucose, yeast extract, dye concentration and inoculum size. They were selected for further optimization.

The statistical analysis of the Plackett - Burman design (Table 2) demonstrated that the model $\mathrm{F}-$ value of 0.71 was significant. The $p$-value $<0.05$ indicated that the model terms were significant.

Table 1- Plackett - Burman experimental design for evaluating factors influencing dye degradation by Coriolus versicolor ML04

\begin{tabular}{|c|c|c|c|c|c|c|c|c|c|c|c|c|}
\hline Run & $\begin{array}{c}\text { Lactose } \\
(\mathrm{g} / \mathrm{L})\end{array}$ & $\begin{array}{c}\text { Glucose } \\
\text { (g/L) }\end{array}$ & $\begin{array}{c}\left(\mathrm{NH}_{4}\right)_{2} \mathrm{SO}_{4} \\
(\mathrm{~g} / \mathrm{L})\end{array}$ & $\begin{array}{c}\mathrm{NH}_{4} \mathrm{NO}_{3} \\
(\mathrm{~g} / \mathrm{L})\end{array}$ & $\begin{array}{c}\text { Tryptone } \\
\text { (g/L) }\end{array}$ & $\begin{array}{l}\text { Yeast } \\
(\mathrm{g} / \mathrm{L})\end{array}$ & $\begin{array}{l}\text { Dye conc } \\
(\mathrm{ppm})\end{array}$ & $\begin{array}{c}\text { Inoculum } \\
\text { size } \\
(\% \mathrm{v} / \mathrm{v}) \\
\end{array}$ & $\begin{array}{l}\text { Incubation } \\
\text { period (h) }\end{array}$ & $\begin{array}{r}\mathrm{CaCl}_{2} \\
(\mathrm{~g} / \mathrm{L})\end{array}$ & $\begin{array}{c}\mathrm{MnSO}_{4} \\
(\mathrm{~g} / \mathrm{L})\end{array}$ & $\begin{array}{c}\text { Decolorization } \\
(\%)\end{array}$ \\
\hline 1 & 3 & 0.5 & 2 & 2 & 2 & 0.25 & 100 & 5 & 96 & 0 & 0.1 & 78.32 \\
\hline 2 & 0.5 & 3 & 0.25 & 2 & 2 & 0.25 & 500 & 20 & 96 & 0 & 0 & 45.54 \\
\hline 3 & 3 & 0.5 & 0.25 & 0.25 & 2 & 0.25 & 500 & 20 & 24 & 0.1 & 0.1 & 38.93 \\
\hline 4 & 0.5 & 0.5 & 2 & 0.25 & 2 & 2 & 100 & 20 & 96 & 0.1 & 0 & 68.22 \\
\hline 5 & 3 & 3 & 0.25 & 2 & 2 & 2 & 100 & 5 & 24 & 0.1 & 0 & 79.36 \\
\hline 6 & 3 & 3 & 0.25 & 0.25 & 0.25 & 2 & 100 & 20 & 96 & 0 & 0.1 & 64.53 \\
\hline 7 & 3 & 3 & 2 & 0.25 & 0.25 & 0.25 & 500 & 5 & 96 & 0.1 & 0 & 31.40 \\
\hline 8 & 0.5 & 3 & 2 & 2 & 0.25 & 0.25 & 100 & 20 & 24 & 0.1 & 0.1 & 61.03 \\
\hline 9 & 0.5 & 0.5 & 0.25 & 0.25 & 0.25 & 0.25 & 100 & 5 & 24 & 0 & 0 & 74.92 \\
\hline 10 & 3 & 0.5 & 2 & 2 & 0.25 & 2 & 500 & 20 & 24 & 0 & 0 & 33.76 \\
\hline 11 & 0.5 & 0.5 & 0.25 & 2 & 0.25 & 2 & 500 & 5 & 96 & 0.1 & 0.1 & 49.32 \\
\hline 12 & 0.5 & 3 & 2 & 0.25 & 2 & 2 & 500 & 5 & 24 & 0 & 0.1 & 47.05 \\
\hline
\end{tabular}

Table 2 - Analysis of variance for dye decolorization by Coriolus versicolor ML04.

\begin{tabular}{ccccccc}
\hline Source & Sum of square & Degree of freedom & Mean square & F - Value & $\boldsymbol{p}$ - Value \\
\hline Model & 8451.06 & 7 & 1334.44 & 0.7183 & 0.0029 & significant \\
B-Glucose & 232.856 & 1 & 287.856 & 6.53482 & 0.0589 & \\
F-Yeast extract & 5863.55 & 1 & 5728.55 & 135.365 & 0.0003 \\
G-Dye concentration & 1325.89 & 1 & 1275.89 & 31.52324 & 0.0047 \\
H-Inoculum size & 7.2383 & 1 & 7.23753 & 0.17001 & 0.7012 \\
Residual & 130.307 & 4 & 52.5768 & & & \\
Cor Total & 8531.36 & 11 & & & & \\
\hline
\end{tabular}


The model's goodness of fit was checked by determination coefficient $\left(\mathrm{R}^{2}\right)$. In this case, the value of $R^{2}(0.98)$ closer to 1 denoted better correlation between the observed and predicted responses. The coefficient of variation $(\mathrm{CV})$ indicated the degree of precision with which the experiments were compared. The lower reliability of the experiment is usually indicated by high value of CV. In the present case, a low CV (6.72) denoted that the experiments performed were highly reliable.

From the analysis, it was inferred that the dye decolorization was supported by glucose, yeast extract, dye concentration and inoculum size as shown by their F-values and $p$-values. Therefore, these variables were considered as highly significant for dye decolorization by $C$. versicolor ML04 and were further investigated with central composite design to find the optimal range of these variables.

Yeast extract has been the most commonly used nitrogen source for dye decolorization process. Many microbial cultures have exhibited effective decolorization of different dyes in presence of yeast extract (He et al., 2004; Moosvi et al., 2005; Khehra et al., 2005). The temperature required to produce the maximum rate of color removal tends to correspond with the optimum cell culture growth temperature of $35-45^{\circ} \mathrm{C}$ (Pearce et al., 2003). On the basis of these reports, SDB medium containing glucose $(0.15 \%)$ and yeast extract $(0.80 \%)$ as cosubstrates with growth at $30{ }^{\circ} \mathrm{C}$ were used. These culture conditions resulted in $78.32 \%$ decolorization of the dye within $48 \mathrm{~h}$. Further incubation did not enhance the decolorization. These results led to plan and carry out a systematic study of dye decolorization process, hence, proceeded with central composite design. The main objective was to determine the optimum operational conditions for the variables or to determine a region that satisfied the operating specifications (Ravikumar et al., 2006).

\section{Central composite design}

The result of 30 run CCD for four variables, glucose concentration, yeast extract concentration, dye concentration and inoculum size chosen for optimization of dye decolorization process are shown in Table 3. It showed the percent of dye decolorization corresponding to combined effect of four components in their specific ranges. The decolorization varied markedly ranging from $32.82-96.21 \%$ in the conditions tested. At high concentration of yeast extract and dye, and low concentration of glucose and inoculum size (run $9)$, lowest $\%$ of decolorization was observed. The decolorization values above $95 \%$ were observed when high concentration of glucose and inoculum size, and low concentration of dye and yeast extract were used (run 30). The experimental results suggested that these variables strongly affected the decolorization process.

The results obtained from the central composite design were fitted to a second order polynomial equation to explain the dependence of decolorization on the medium components.

$\mathrm{Y}=+91.33+1.08 \mathrm{~A}+1.08 \mathrm{~B}-2.67 \mathrm{C}+1.25 \mathrm{D}$ $+5.75 \mathrm{AB}+2.63 \mathrm{AC}-2.00 \mathrm{AD}-0.62 \mathrm{BC}-1.75$ $\mathrm{BD}-2.37 \mathrm{CD}-3.79 \mathrm{~A}^{2}-1.04 \mathrm{~B}^{2}-12.79 \mathrm{C}^{2}-$ $17.29 \mathrm{D}^{2}$

Where $\mathrm{Y}$ is the predicted response $(\%$ decolorization), $\mathrm{A}, \mathrm{B}, \mathrm{C}$ and $\mathrm{D}$ are the coded values of glucose concentration, yeast extract concentration, dye concentration and inoculum size respectively.

The analysis of variance of the quadratic regression model suggested that the model was very significant as was evident from the Fisher's F - test (Table 4). The model's goodness of fit was checked by determination coefficient $\left(\mathrm{R}^{2}\right)$. In this case, the value of $R^{2}(0.79)$ closer to 1 denoted better correlation between the observed and predicted responses. The low CV (3.45) denoted that the experiments performed were highly reliable. The $p$-values denoted the significance of the coefficients and also the importance in understanding the pattern of the mutual interactions between the variables. The choices for level combinations of the four variables; glucose, yeast extract, inoculum size and dye concentration could be made easily from contour plots and response surface curves (Fig. 1). 
Table 3 - Central composite design for decolorization of Blue BB by Coriolus versicolor ML04.

\begin{tabular}{|c|c|c|c|c|c|c|}
\hline \multirow{2}{*}{ Run } & \multirow{2}{*}{ Glucose $(g / L)$} & \multirow{2}{*}{ Yeast (g/L) } & \multirow{2}{*}{$\begin{array}{c}\text { Dye conc } \\
(\mathbf{p p m})\end{array}$} & \multirow{2}{*}{$\begin{array}{c}\text { Inoculum size (\% } \\
\text { v/v) }\end{array}$} & \multicolumn{2}{|c|}{ Decolorization (\%) } \\
\hline & & & & & Experimental & Predicted \\
\hline 1 & 0 & 0 & 0 & 0 & 95.43 & 91.33333 \\
\hline 2 & 0 & 0 & 2 & 0 & 43.23 & 34.83333 \\
\hline 3 & -1 & -1 & -1 & -1 & 56.64 & 57.29167 \\
\hline 4 & -2 & 0 & 0 & 0 & 78.02 & 74 \\
\hline 5 & -1 & -1 & -1 & 1 & 63.54 & 72.04167 \\
\hline 6 & 1 & 1 & 1 & 1 & 54.12 & 58.79167 \\
\hline 7 & 0 & 0 & 0 & 0 & 89.35 & 91.33333 \\
\hline 8 & 1 & 1 & -1 & -1 & 42.98 & 46.70833 \\
\hline 9 & -1 & 1 & 1 & -1 & 32.82 & 45.625 \\
\hline 10 & -1 & 1 & -1 & -1 & 68.81 & 52.70833 \\
\hline 11 & 1 & -1 & 1 & -1 & 49.02 & 52.625 \\
\hline 12 & 2 & 0 & 0 & 0 & 76.26 & 78.33333 \\
\hline 13 & -1 & -1 & 1 & -1 & 68.02 & 52.70833 \\
\hline 14 & 0 & 0 & -2 & 0 & 39.05 & 45.5 \\
\hline 15 & 1 & 1 & 1 & -1 & 92.32 & 88.54167 \\
\hline 16 & -1 & -1 & 1 & 1 & 45.91 & 57.95833 \\
\hline 17 & 0 & 0 & 0 & 0 & 94.94 & 91.33333 \\
\hline 18 & 1 & -1 & 1 & 1 & 49.81 & 49.875 \\
\hline 19 & -1 & 1 & 1 & 1 & 43.03 & 43.875 \\
\hline 20 & 0 & 0 & 0 & 0 & 94.09 & 91.33333 \\
\hline 21 & 0 & 0 & 0 & 0 & 90.33 & 91.33333 \\
\hline 22 & 0 & 2 & 0 & 0 & 87.38 & 89.33333 \\
\hline 23 & 1 & -1 & -1 & -1 & 62.3 & 65.125 \\
\hline 24 & 0 & 0 & 0 & -2 & 0 & 0 \\
\hline 25 & 0 & -2 & 0 & 0 & 89.73 & 85 \\
\hline 26 & 1 & 1 & -1 & 1 & 64.89 & 64.875 \\
\hline 27 & 0 & 0 & 0 & 2 & 46.32 & 44.66667 \\
\hline 28 & -1 & 1 & -1 & 1 & 58.01 & 60.45833 \\
\hline 29 & 1 & -1 & -1 & 1 & 51.05 & 53.45833 \\
\hline 30 & 0 & 0 & 0 & 0 & 96.21 & 91.33333 \\
\hline
\end{tabular}

Table 4 - ANOVA of \% decolorization for Blue BB: effect of glucose, yeast extract, dye concentration and inoculum size.

\begin{tabular}{|c|c|c|c|c|c|c|}
\hline Source & Sum of square & Degree of freedom & Mean square & F - Value & P-Value & \\
\hline Model & 12510.8 & 14 & 893.627 & 4.04427447 & 0.0055 & significant \\
\hline A-Glucose & 28.1667 & 1 & 28.1667 & 0.12747341 & 0.7260 & \\
\hline B-Yeast & 28.1667 & 1 & 28.1667 & 0.12747341 & 0.7260 & \\
\hline C-Dye concentration & 170.667 & 1 & 170.667 & 0.77238328 & 0.3933 & \\
\hline D-Inoculum size & 37.5 & 1 & 37.5 & 0.16971312 & 0.6862 & \\
\hline $\mathrm{AB}$ & 529 & 1 & 529 & 2.39408644 & 0.1426 & \\
\hline $\mathrm{AC}$ & 110.25 & 1 & 110.25 & 0.49895658 & 0.4908 & \\
\hline $\mathrm{AD}$ & 64 & 1 & 64 & 0.28964373 & 0.5983 & \\
\hline $\mathrm{BC}$ & 6.25 & 1 & 6.25 & 0.02828552 & 0.8687 & \\
\hline $\mathrm{BD}$ & 49 & 1 & 49 & 0.22175848 & 0.6445 & \\
\hline $\mathrm{CD}$ & 90.25 & 1 & 90.25 & 0.40844291 & 0.5324 & \\
\hline $\mathrm{A}^{2}$ & 394.333 & 1 & 394.333 & 1.78462776 & 0.2015 & \\
\hline $\mathrm{B}^{2}$ & 29.7619 & 1 & 29.7619 & 0.13469295 & 0.7187 & \\
\hline$C^{2}$ & 4488.05 & 1 & 4488.05 & 20.3114819 & 0.0004 & \\
\hline $\mathrm{D}^{2}$ & 8201.19 & 1 & 8201.19 & 37.1159904 & $<0.0001$ & \\
\hline Residual & 3314.42 & 15 & 220.961 & & & \\
\hline Lack of Fit & 3111.08 & 10 & 311.108 & 7.65020492 & 0.0183 & significant \\
\hline Pure Error & 203.333 & 5 & 40.6667 & & & \\
\hline Cor Total & 15825.2 & 29 & & & & \\
\hline
\end{tabular}




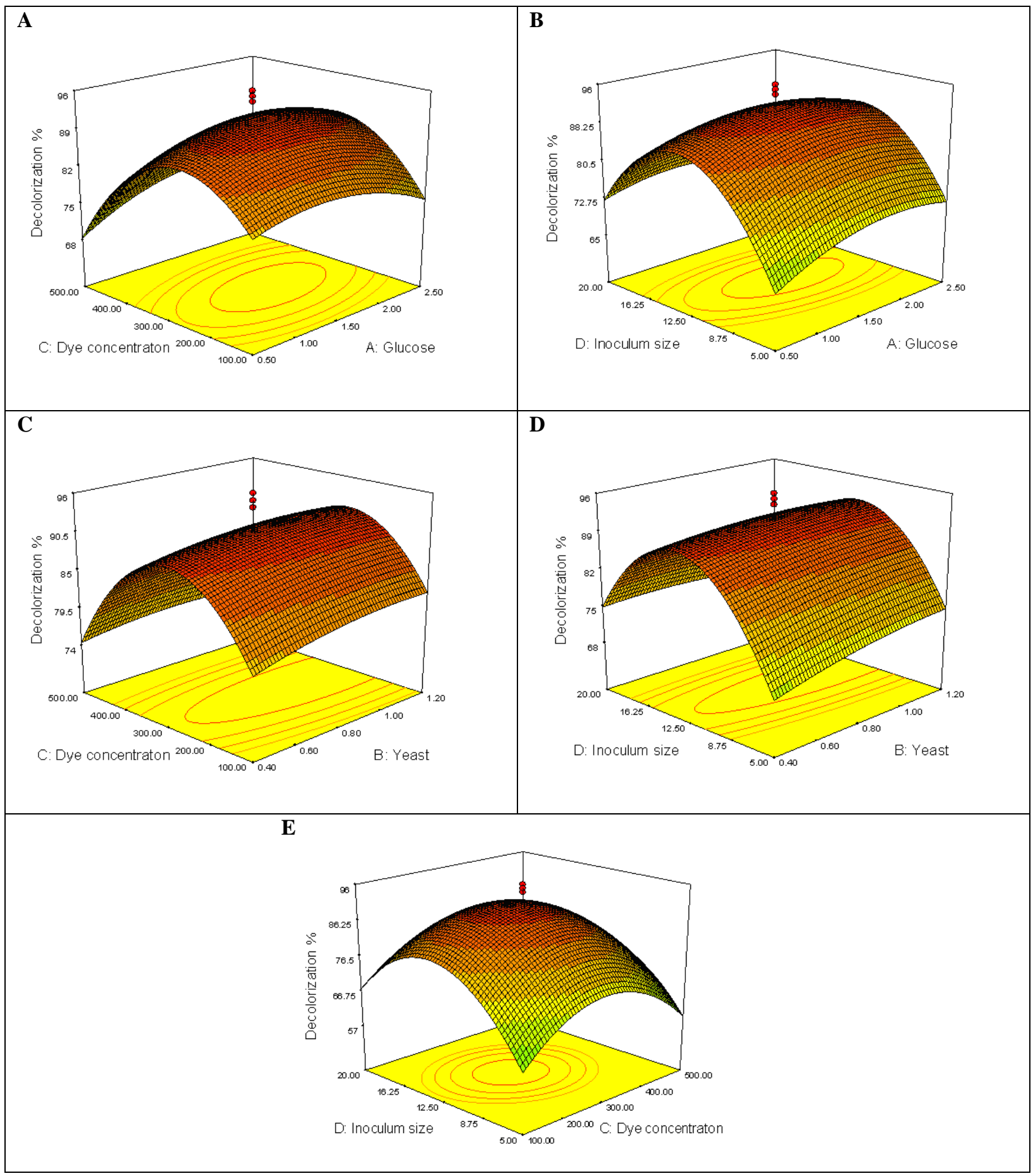

Figure 1 - Response surface and contour plot of the combined effect of (A) glucose, dye concentration; (B) glucose, inoculum size; (C) yeast extract, dye concentration; (D) yeast extract, inoculum size; (E) dye concentration, inoculum size on dye decolorization by Coriolus versicolor ML04. 
Pearce et al. (2003) reported that the dye concentration could influence the efficiency of decolorization through a combination of factors, including the toxicity of the dye. Low decolorization efficiency at high dye stuff concentration has been reported for different cultures such as Kruthia sp. (Sani \& Banerjee, 1999) and Pseudomonas aeruginosa NBAR12 (Bhatt et al., 2005). Both, glucose and the inoculum size had synergistic as well as antagonistic effect on maximizing the decolorization. Initially with increase in concentration of glucose and inoculum size, there was increase in the decolorization, but higher concentrations were found to be inhibitory. Knapp and Newby (1995) and Chen et al. (2003) have also reported decrease in dye decolorization efficiency at high glucose concentrations. Therefore, the maximum decolorization was achieved at the optimum concentration of the two variables (glucose and inoculum size). Bhatt et al. (2005) observed decrease in dye decolorization efficiency at high concentration of yeast extract. Hence, a proper choice of level combination of glucose and yeast extract is desirable for maximizing the decolorization. The nutrient requirement for optimum decolorization depends on the nature of the microbial species employed.

This study demonstrated the potential of the fungus $C$. versicolor $M L 04$ to be exploited for the dye decolorization and degradation and effect of statistical optimization design of the medium factors for this process.

\section{CONCLUSIONS}

The application of $C$. versicolor ML04 to decolorize the synthetic dye Blue BB seemed to be one of a pragmatic approach. This study showed that the response surface methodology was an appropriate method to optimize the culture conditions for obtaining the maximum decolorization of the dye. By applying the central composite design and RSM to the optimization experiments, the process variables were investigated to achieve the maximum decolorization of $96.21 \%$. The experimental and predicted values were very close, which reflected the accuracy and the applicability of RSM. Moreover, the ability of $C$. versicolor ML04 to decolorize Blue BB of more than $96 \%$ indicated its potential for decolorizing the dyeing effluents.

\section{ACKNOWLEDGEMENTS}

The authors are thankful to the authorities of Bharathiar University, Coimbatore, Tamil Nadu, India for providing the infrastructure facilities for this study.

\section{REFERENCES}

Bhatt, N., Patel, K.C., Keharia, H., Madamwar, D. (2005), Decolorization of diazo dye Reactive Blue 172 by Pseudomonas aeruginosa NBAR12. J. Basic Microbiol., 45, 407-418.

Box, G.E.P., Hunter, J.S. (1957), Multi - factor experimental designs for exploring response surfaces. Ann. Math. Stat., 28, 195 - 241.

Box, G.E.P., Wilson, K.B. (1951), On the experimental attainment of optimum conditions, J. R. Stat. Soc. Ser. B-Stat. Meth., 13 (1), 1-45.

Chang, J.S., Chou, C., Chen, S.Y. (2001), Decolorization of azo dyes with immobilized Pseudomonas luteola. Process Biochem., 36, 757763.

Chen, D., Han Y., Gu, Z. (2006), Application of statistical methodology to the optimization of fermentative medium for carotenoids production by Rhodobacter sphaeroides. Process Biochem., 41, 1773 - 1778.

Coughlin, M.F., Kinkle, B.K., Bishop, P.L. (1999), Degradation of azo dyes containing aminonaphthol by Sphingomonas sp. strain 1CX. J. Ind. Microbiol. Biotechnol., 23, 341-346.

He, F., Hu, W., Li, Y. (2004), Biodegradation mechanisms and kinetics of azo dye 4BS by a microbial consortium. Chemosphere, 57, 293-301.

Jadhav, J.P., Govindwar, S.P. (2006), Biotransformation of malachite green by Saccharomyces cerevisiae. Yeast, 23, 315 - 323.

Keck, A., Klein, J., Kuelidh, M., Stolz, A., Knackmuss, H.J., Matles, R. (1997), Reduction of azo dyes by reox mediators originating in the Naphtahlenesulfonic acid degradation pathway of Sphingomonas sp. strain BN-6. Appl. Environ. Microbiol., 63(9), 3684 - 3690.

Khehra, M.S., Saini, H.S., Sharma, D.K., Chadha, B.S., Chimmi, S.S. (2005), Decolorization of various azo dyes by bacterial consortium. Dyes Pig., 67, 55-61.

Knapp, J.S., Newby, P.S. (1995), The microbiological decolorization of an industrial effluent containing a diazo linked chromophore. Water Res., 7, 1807-1809.

Lacina, C., Germain, G., Spiros, A.N. (2003). Utilization of fungi for biotreatment of raw wastewaters. Afr. J. Biotechnol., 2, 620-630.

Mohana, S., Desai, C., Madamwar, D. (2007), Biodegradation and decolorization of anaerobically treated distillery spent wash by a novel bacterial consortium. Bioresour. Technol., 98, 333-339. 
Moosvi, S., Keharia, H., Madamwar, D. (2005), Decolorization of textile dye Reactive Violet 5 by a new isolated bacterial consortium RVM 11.1. World J. Microbiol. Biotechnol., 21, 667-672.

Pearce, C.I., Lloyd, J.R., Guthrie, J.T. (2003), The removal of colour from textile waste waters using whole bacterial cells: a review. Dyes Pig., 58, 179196.

Ravikumar, K., Ramaligam, S., Krishnan, S., Balu, K. (2006), Application of response surface methodology to optimize the process variables for Reactive Red and Acid Brown dye removal using a novel biosorbent. Dyes Pig., 70, 18-26.
Sani, R.K., Banerjee, U.C. (1999), Decolorization of triphenylmethane dyes and textile and dye stuff effluent by Kruthia sp. Enzyme Microb. Technol., 24, 433-437.

Wasenberg, D., Kyriakides, I., Agathos, S.N. (2003). White rot fungi and their enzymes for the treatment of industrial dye effluents. Biotechnol. Adv, 22, 161187.

Received: May 18, 2009; Revised: January 06, 2010; Accepted: April 14, 2010. 